\title{
Editorial
}

\section{SPEMD 2018-2019: Objetivos programáticos do mandato do centenário}

\section{SPEMD 2018-2019: Program objectives of the centennial term of office}

\author{
João Carlos Sampaio Fernandes \\ Presidente da Sociedade Portuguesa de Estomatologia e Medicina Dentária (SPEMD)
}

A SPEMD, enquanto Sociedade Científica com uma história inigualável de dignificação da Medicina Dentária e da Estomatologia Portuguesas tem hoje um visível protagonismo científico. Ao longo dos últimos mandatos muito foi feito para a tornar uma instituição moderna, com instalações condignas, e fundamental quanto à formação humana, profissional e científica dos seus associados.

$\mathrm{Na}$ altura em que assumimos a sua Direção, importa realçar alguns dos aspetos que consideramos importante desenvolver:

1. Organizar o seu Congresso Anual, que decorre sucessivamente nas cidades de Lisboa, Porto e Coimbra, e promover ações de formação científica de qualidade, em diferentes locais do país.

2. Promover as Comemorações de Santa Apolónia, atividade lúdica e cultural, e de são convívio familiar, que sempre foi apanágio da SPEMD e que esperamos continue por longos anos.

3. Representar, em parceria com a OMD, os seus associados a nível internacional, nomeadamente na Federação Dentária Internacional (FDI).

4. Valorizar as parcerias institucionais e as Sociedades Afiliadas, e que atualmente são a Sociedade Portuguesa de Ortopedia Dentofacial (SPODF), a Sociedade Portuguesa de Endodontologia (SPE), a Sociedade Portuguesa de Terapia da Fala (SPTF), a Sociedade Portuguesa de Disfunção Temporomandibular e Dor Orfoacial (SPDOF), a Faculdade de Medicina Dentária da Universidade do Porto (FMDUP), a Faculdade de Medicina Dentária da Universidade de Lisboa (FMDUL), a Universidade Católica Portuguesa - Pólo de Viseu, a Cooperativa de Ensino Superior Egas Moniz, a Miúdos Otimistas Miúdos Saudáveis (MOMS), a Associação Portuguesa de Higienistas Orais (APHO), a European So- ciety of Cosmetic Dentistry /ESCD), o Grupo IFE/Revista Saúde Oral e o Grupo Maxillaris.

5. Publicar esta Revista de forma regular, com conteúdos científicos sérios e originais, e sempre após aprovação por revisores de elevado mérito técnico e científico. Importa realçar que a revista atingiu já um nível elevado de indexação científica, mas que se torna imperioso conseguir maior reconhecimento internacional. É gratificante ouvir de inúmeros colegas elogios ao seu conteúdo científico, e os autores reconhecerem que a exigência dos revisores tem levado a que os artigos científicos sejam vistos de forma cada vez mais prestigiada. Vamos continuar a pugnar pela publicação dos artigos científicos que a comunidade médico-dentária, incluindo os estudantes, portuguesa e de cada vez mais países, nos confiam e que muito nos gratificam. Função de alta relevância, tendo em conta que, em Portugal, as alternativas quase não existem.

6. Um dos pontos que interessa tornar claro prende-se com as vantagens de ser sócio da SPEMD. Nesse aspeto, há anos que atribuímos o Patrocínio Científico que valoriza a formação contínua e torna esses eventos menos onerosos para os nossos sócios, apoiamos monetariamente sócios que se desloquem ao estrangeiro para apresentar trabalhos científicos, e atribuímos os Prémios Congresso SPEMD e o Prémio de Investigação.

Outra forma de valorizar a condição de associado é promover ainda mais parcerias com Sociedades Científicas, portuguesas e estrangeiras. A mais recente foi a European Society of Cosmetic Dentistry (ESCD).

Tudo faremos para que nos possamos orgulhar de pertencer à SPEMD, a mais antiga sociedade médica portuguesa, que em 2019 completa 100 anos. 